\title{
Ambiances
}

anbiances Environnement sensible, architecture et espace urbain Redécouvertes | 2016

\section{Atmospheric Spaces}

Espaces atmosphériques

\section{Hermann Schmitz}

Translator: Margret Vince

\section{OpenEdition}

\section{Journals}

Electronic version

URL: http://journals.openedition.org/ambiances/711

DOI: $10.4000 / a m b i a n c e s .711$

ISSN: 2266-839X

\section{Publisher:}

Direction Générale des Patrimoines - DAPA - MCC, UMR 1563 - Ambiances Architectures Urbanités (AAU)

\section{Electronic reference}

Hermann Schmitz, «Atmospheric Spaces », Ambiances [Online], Rediscovering, Online since 27 April 2016, connection on 19 April 2019. URL : http://journals.openedition.org/ambiances/711 ; DOI 10.4000/ambiances.711

This text was automatically generated on 19 April 2019

\section{(c) (i) (9)}

Ambiances is licensed under a Creative Commons Attribution-NonCommercial-NoDerivatives 4.0 International License. 


\title{
Atmospheric Spaces
}

\author{
Espaces atmosphériques
}

\section{Hermann Schmitz}

Translation : Margret Vince

\section{REFERENCES}

Schmitz, Hermann. 2012. Atmosphärische Räume. In : Goetz, Rainer ; Graupner, Stefan (eds.). Atmosphäre(n) II. Interdisziplinäre Annäherungen an einen unscharfen Begriff. München : kopaed. p. 17-30.

\section{AUTHOR'S NOTE}

Traduction Margret Vince, en collaboration avec Rainer Kazig

1 In Ancient Greece, during the $5^{\text {th }}$ century BCE a change occurred in people's understanding of the world and themselves that would prove fateful for all of subsequent history. The world is split, in that each conscious being obtains an excerpt from it as his private inner world, in which his entire experience is contained and sealed off from the outside world. Its name is "psyche", "soul". At the start of the century, this soul, which until then was life or the spirit of the dead, still lacked isolation; Heraclitus says : "You shall never find the limits of the soul on your wanderings, no matter how many roads you travel" (Diels \& Kranz, 1956, p. 161) ${ }^{1}$. From Sophocles, in the second half of the century, in this isolated verse from the lost Manteis, the expression survives : "to open the closed gate of the soul" (Nauck, 1964, p. 217). ${ }^{2}$ The split in the world lies between these two testimonies. The external world that remains between them after taking away all the inner worlds was even then, with Democritus, and later with Plato and his successors, pared down to a few characteristic types and their notional bearers. The waste left over from this paring down is disposed of by transportation into the souls, either deliberately, as in the specific sensory qualities, or on the quiet, in that the reserves are forgotten and 
are unexpectedly accommodated, in modified form, in the souls. In this way, the perceptible felt body [Leib] and corporeal [leiblich] communication, the emotions as atmospheres and atmospheres of other kinds, meaningful impressions and other significant situations, as well as other things are displaced from one's attention; what remain are inner worlds for self-control and an external world for mastery of the world, first by God, then by humans and their works.

2 At the same time, belonging to it analogously on top of that, Greek geometry developed as the first deductive science, taking as its subject the space on the area, in that twodimensional shapes such as circles, triangles and conic sections as well as bodies are viewed in terms of their surfaces. Since then, the notion of space has assumed, as if it were self-evident, that areas exist in space. This notion later matured in the form of analytical coordinate geometry which, with its nets developed in the area, spans the space and creates the schema of a determination of location, as precise as desired. This fixing on a type of space that contains areas has far-reaching consequences. Areas are readily accessible, sometimes as smooth surfaces such as the hairless skin of a human being, sometimes as areas that do not demarcate anything, such as some patches of light. One needs areas in order to arrive, moving downwards, at lines (as edges) and points (as corners). Without areas and lines there is no possibility of interpreting solid bodies as three-dimensional volumes. Without sections, one cannot derive any divisibility from the extension of bodies. But above all, one needs lines and thus areas in order to introduce locations which permit one to say where something is. This introduction of locations starts out from visual targets which are placed in relation to one another through lines that join them. In contrast to the direction of gaze, these connecting tracks are reversible, i.e. one can always traverse them in the opposite direction. Through this, it becomes possible to read off distances and positions from them. With the aid of distances and positions, it is possible to introduce a system of locations which are mutually determined by the positions and distances of objects situated on them - a locational space [Ortsraum], as I call it. We have the access to areas to thank for all these characteristics and orientation aids of the space that is familiar to us.

3 There are, however, also spaces without area. One example is the space of sound. I am thinking not so much of the signals for direction and distance relating to the source of the sound, but rather of the space spanned by the rhythmic and tonal movement suggestions of the sound, such as piercing noise, diminishing echo, rising and falling, pressing and circling, everything that jumps from the sound to those who are dancing and marching, likewise of the synaesthetic mass properties of the sound as a far-reaching, sonorous resonance of a gong or a shrill, sharp whistle, etc. The sound has volume, but not a three-dimensional volume, because there are no areas. Very close to it is the arealess space of the readily remembered silence, which as a ceremonial silence is broad and dense, as an oppressive silence is close and even denser, as the silence of an untouched morning is broad and delicate. Other examples are the space of the weather, which one might experience for example as a loosely filled expanse when emerging from a stifling room to the outdoors; the space of the unobtrusive backdrop which one continually claims through small movements of straightening up, leaning back, stretching, and through which one hurries energetically, dancing backwards, because there are no concerns about two-dimensionally delimited obstacles; the space of the wind striking you head on, which is perceived as movement without any change in location if one takes it as it comes, and does not supplement it to become moved air ; the space of the freely 
unfolding gesture, the space of the water for the swimmer who struggles against a resisting volume that is without areas or lines, but which has directions of striving forward or flowing against, or who calmly lets himself be carried by it. Such area-less spaces are not merely shadow-like side-effects and symptoms of the locational space that is familiar to us, but are rather its indispensable preconditions, not just psychologically or anthropologically, but even logically. One can show that a locational space cannot even be introduced without borrowing something from spaces that are without location, because they are without area. In the locational space, stillness and movement are defined as staying in one location and changing location. Furthermore, locations are determined, i.e. identified, through their position and distance from static objects. For if these objects were to move, but the identified locations did not move along with them, their positions and distances from the reference objects would change. The objects located on them would thus have changed their location, even if they had remained where they were. Stillness and movement would no longer be distinguishable, and this cannot be. Determining location thus presupposes that the reference objects are stationary. On the other hand, stillness in locational space presupposes locations, if it is understood as remaining in one place. Stillness then presupposes the location, but the location presupposes stillness, and what arises is a circular definition which thwarts the introduction of a locational space if one cannot fall back on an understanding of stillness that precedes the locational space. Such an understanding is provided by area-less spaces, e.g. as still water, calm silence, evening repose, resting when tired. One must start out from such morphic experiences of stillness in order to find reference objects through which one can set up a locational space with positions and distances; in this, these reference objects can then be determined themselves by locations, and then secondarily the stillness of the reference objects can count as remaining at these locations.

The two most important types of area-less spaces are the space of the felt body and the space of emotions as atmospheres. I define the felt body of a person as the epitome of everything that he himself can perceive as belonging to himself, in the vicinity - not always within the boundaries - of his material body [Körper], without making use of the five senses of sight, hearing, touch, smell, taste and of the perceptive material body schema (the habitual image of a person's own material body) that has been obtained from his or her experiences, particularly those of sight and touch. These include first of all the purely corporeal stirrings such as fright, anxiety, pain, hunger, thirst, itching, sharp pains, disgust, vigour, fatigue ; secondly, the corporeal stirrings which are the affective marks of emotions, e.g. of joy, sadness, anger, shame, fear, courage, compassion, contentedness, despair ; thirdly, the perceived voluntary and involuntary movements such as walking, grasping, jumping, dancing, shivering, twitching, swallowing; and fourthly, the irreversible corporeal directions, sometimes occurring without movement, as when one gazes, sometimes tied to movements, as in breathing out and swallowing. All these corporeal events are area-less. One cannot perceive any areas on one's own felt body. One can see them and feel them only on one's own material body. The felt body is usually a surging of blurred islands, amongst which individual ones stand out through consistency, structure and function. This includes the island of breathing in the region of the chest or abdomen. It forms itself anew with every intake of breath, through the enfolding of constricting tension with widening expansion, wherein initially the expansion takes the lead, from which the predominance is gradually displaced towards tension, until this threatens to become unbearable and its predominance is carried away via the direction of breathing out, which leads irreversibly from constriction into broadness, with which the 
felt body island collapses, only to be formed anew shortly after. Through this, one can see what is a volume without area, and therefore a volume that is not three-dimensional either, but which is also - through the enfolding of contraction and expansion - a dynamic corporeal volume for the vital drive.

The vital drive goes beyond the boundaries of one's own felt body and connects felt bodies to one another, as well as to incorporeal figures through a common vital drive in the encorporation [Einleibung] which is either antagonistic (through at least one-sided attention to a partner) or showing solidarity (without such attention). I shall make do here with an example of antagonistic encorporation, namely the involuntary ballet that is enacted on the populated streets of cities when people hurry towards one another in crowds. Each has in mind only his own objective, for example an intended purchase, and graces the others with fleeting, almost careless glances, but which are nonetheless sufficient to allow him to pass them without colliding with them, in the course of which he must take account of the imminent routes of the next person as well as of those appearing behind him and alongside, without noticing the position and distance of his own material body relative to them, and the parts of his material body - feet, shoulders, arms of his own material body - that are decisive for evasion. This succeeds because the glances follow on from one another and the movement suggestions (the clear signs of imminent movement by the oncoming people) transfer into the material body schema of the motor system which controls expediently integrated movements, whose directions are not - like those of the perceptive material body schema - reversible, but are irreversible. I shall return to that. Encorporation also exists in relation to incorporeal figures, such as a stone or snowball flying towards one, which one skilfully evades like oncoming people, without taking note of the position and distance of one's own material body parts. Such encorporation into something incorporeal is enabled by bridge qualities, which can be perceived both on one's own felt body and on figures that one encounters. Such bridge qualities are movement suggestions and synesthetic characteristics. Synesthetic characteristics are properties which run through all specific senses and often, but not always, bear the names of specific sensory qualities, but as the breadth, weight and density of readily remembered stillness, they can also make do entirely without sensory qualities. The gait of a person is a good example of movement suggestions and synesthetic characteristics which can be sensed on one's own felt body, just as the gait of another person can be perceived, for example as nimble, lithe, tense, lively, jaunty or as soft, ponderous, heavy, shuffling, dragging, ungainly etc.

6 With the corporeal stirrings, we encounter atmospheres for the first time. There are partial corporeal stirrings that are accommodated on individual islands of the felt body, such as headache, stomach ache or tired legs. There are also holistic corporeal stirrings, such as a climate into which the whole felt body is immersed, without distribution to islands. Scheler (1954, p. 350-354) spoke of feelings of being alive [Lebensgefühle]. One example is weariness, which is different from fatigue. Fatigue can be holistic or partial, but weariness is only holistic. Fatigue requires rest, and is satisfied by it. Weariness is alleviated as little by rest as it is by movement; it is a sensitive weakening of vitality without regard to the movement status of the felt body. Another example is the holistic pleasure experienced when lazing in the sun or in the bath. That which is called a person's form on the day belongs here just as the gradual, easily disrupted process of livening up experienced by many people in the mornings - the so-called morning grouches. Such feelings of being alive are holistic corporeal stirrings. They are atmospheres 
of the felt body. The meaning of the word "atmosphere" in the most general interpretation that is necessary for the phenomenology of spatiality can be expressed thus : an atmosphere is a total or partial, but in any case comprehensive, occupation of an area-less space in the sphere of that which is experienced as being present. I speak of "occupation" rather than filling, so that an atmosphere of emptiness can be taken into account also. With "comprehensive", I wish to indicate that it is not just individual points that are occupied, but extended fields, in which many points are accommodated. Nevertheless, not every such atmosphere needs to occupy totally the space of experienced presence, or even to claim this. This is not the case with corporeal atmospheres, what Scheler calls feelings of being alive. The weariness of a felt body is compatible with surroundings that are bursting with vitality. The pleasure experienced in the bath or a warm room does not extend beyond their margins ; it may be bitterly cold outside. In this respect, atmospheres of the felt body differ from atmospheres of emotion. Besides corporeal pleasure, there is a pleasure as an emotion, for example the feeling of being secure in the love of a person, or of a harmonious family circle. For this, one does not need a bathtub or a warm room ; it is everywhere one goes, borderless in the space of experienced presence.

7 That atmospheres of emotion fill the area-less space of experienced presence entirely, or at least claim to fill it, I shall demonstrate by the social contrast of emotions. To this end, I shall compare two emotions, joy and sorrow, with two merely corporeal stirrings, vigour and weariness. Joy and vigour, sorrow and weariness are related; joy can be felt with vigour, and sorrow with weariness. I now imagine that a person who is feeling joyful finds himself inadvertently in the company of deeply sorrowful people who are immersed in their sorrow. Given a certain amount of sensitivity, he will dampen the lively expression of his joy somewhat, and perhaps even hold it back modestly, and retreat. His behaviour will turn out to be different if he, as a person full of vigour, finds himself in the company of weary people. If he wants something from them, he will not allow himself to be subdued by them, but will attempt to stir the weary people by appealing to them or even grabbing them, and if he does not achieve anything, he will more likely be prepared to actively help them, by offering them refreshment or calling a doctor, and so on. This difference in the degree of contrast requires explanation. The respect for human dignity is not sufficient here. It would benefit both the weary and the sorrowful people, and rather lead to grasping hold of them, in order to raise them up and thus give them back their attitude of pride and dignity. A stronger inhibition is necessary, one that outweighs the respect for human dignity, in order to prompt the joyful person to leave the sorrowful people alone. This can only be the authority of sorrow itself, of an atmosphere that emanates from the people who are immersed in it, which makes the claim to occupy the space of experienced presence entirely, and with the strength of this claim defeats the claim of joyfulness, which in this situation is equal but carries less weight. Weariness, on the other hand, does not make such a claim, since the merely corporeal stirrings, even as holistic ones, form atmospheres that are delimited in the surroundings, and nor do they have the authority of emotions.

8 Since the split in the world that occurred in the fifth century BCE, we have become accustomed to categorising the emotions as passiones animae, affects or passions of the soul, and to assign them to the closed, private inner world of the conscious being - in contrast to Empedocles who, still in those times, claimed to be the first to have recognised that the love that one sees swirling outside is the same as that which, 
implanted in the limbs of mortals, works towards them harbouring friendly attitudes and performing peaceable works. ${ }^{3}$ The introjection of the emotions to which the humanity of classical Greek philosophy around the time of Plato and Aristotle subscribed is an error; it already fails through the fact that the soul, or whatever one wishes to call a closed private inner world of all experience that is introjected into it, does not exist, as is demonstrated in particular by the fact that the relationship of the conscious being to his soul cannot be conclusively constructed (Schmitz 2009, p. 29-45; 2010, p. 145-163). Emotions are atmospheres in an area-less space which can be congruent with the locational space that covers an area, just like the area-less spaces of sound and silence, but which is also capable of extending beyond that. The atmospheres of emotion are either merely perceived, or they move one in a corporeally perceptible way; in this case, they are felt in affective impingement, as the emotions that one has oneself.

The area-less emotional space has three layers. The base layer is formed by the pure moods, which with mere breadth, but still without direction, underpin all other emotions. There are two pure moods : contentedness and despair. Despair is the mood of emptiness, like the acedia of the Desert Fathers, like the ennui of the French, a boredom that is mixed with disgust. It is sometimes formed by reflection on the meaningless nature of life and activity, but in other cases it can also arise spontaneously, for example in an unsettlingly pale and cool evening twilight, or on a cold, wet November morning in the ugly sea of houses of a big city, or on a railway station. It is oppressive, but not depressing like sorrow, but anchorless, a falling into emptiness. The opposite mood, contentedness, is the sense of being sustained by a dense wealth of emotion, such as the sense of feeling secure in the love of a person or a harmonious family circle, or in calm, not arrogant, but composed self-confidence. The second layer consists of pure stimuli ; these are emotions whose atmosphere is pervaded by directions, but is not centred on a theme. These include abstract joy and melancholy, apprehension and longing, discontent and mistrust, which are just looking for triggers, and are characterised by presentiment, a sense of anticipation. The third layer is formed by the thematically centred emotions, in which the directed stimuli are pulled together around a theme. They are often passed off as intentional emotions, related to an object, and are then also often taken to be actual emotions, but this characterisation is not sufficient, since talk of the object of an emotion is mostly ambiguous, namely when the thematic centre is split into the area of condensing and the point of anchorage. Thus joy about something, namely a point of anchorage for the joy, such as success at work, is different from joy of something, an area of condensing, for example joy of a beautiful landscape, which one does not experience joy about. In the case of a murderous attack, the area of condensing is the fear of the attackers, and the point of anchorage is death. If, in a preliminary form of fear without a point of anchorage, the area of condensing is experienced with corporeal anxiety, the result is horror, which is rounded off into fear when a point of anchorage is added.

In addition to the emotions as atmospheres with the tendency to total expansion in the space of experienced presence, there are also other such atmospheres which are not, or not always, emotions. The most obvious example is the weather, as it is actually given to human perception and sensing, and which still forms the most obvious substance of conversation between strangers, in other words before any constructive attempts at division into a physical and a psychological part. Another example is stillness, either on a broad plain or at night. Weather and stillness can be emotions, for example as cheerfully radiant, constricting, oppressive, or solemn atmospheres; often, however, this 
emotionally charged nature is missing. The difference lies in the way in which the atmospheres become corporeally tangible. The affective impact of emotions is feeling moved, in the sense that this feeling of being affected only then becomes one's own genuine feeling of the emotion when the affected person first of all goes along with the stimulus that the feeling gives him, and only subsequently has the opportunity to deal with it through surrender or resistance. By contrast, whoever welcomes the feeling, right at the threshold of its entry into being affected in a corporeally affective way, with a ready-made stance, will either only be graced with a fleeting trace and will not be moved by it, or he will just act as if he felt and were moved by the emotion. In the case of the mere corporeal stirrings and the totally space-filling atmospheres which are not emotions, this sequence does not apply. A weather which is not an emotion can certainly have a corporeally affective impact, so that for example one curses it and wishes for rain instead, or conversely for dry conditions, but one cannot speak here of being moved by it, which would be genuine only if one were first of all to go along with a stimulus provided by the weather and only afterwards had the opportunity to deal with it through surrender or resistance.

11 In area-less spaces one can live and orientate oneself without requiring an area. All one needs for this is a web of directions of various kinds, which I now intend to categorise. In first position are the corporeal directions, which are indivisibly extended and which lead irreversibly from constriction to broadness. Of these, the gaze and the directions of the material body schema for the motor system are important for orientation. Apart from the perceptive material body schema, which is organised at the level of locational space through positions and distances via reversible connections, the human being (like the animal) has a material body schema for the motor system, which for example steps into action if, in the case of itching or burning on the skin, the dominant hand, without being located according to distance and position, is led directly and surely to the irritated point on the skin, in order to brush off or crush the parasite that is anticipated to be there. The material body schema for the motor system, which directs all the expediently coordinated movements of the material body, is based on irreversible directions, which call up the material body parts that are relevant for the movement in the precisely determined vicinity and distance, but cannot be reversed in order, starting out from the material body parts, to find the reference point from which, for example, the right hand is always on the right, the foot is always further away than the knee. The gaze is itself one of the directions of the material body schema for the motor system, which - independently of the gaze, for example - direct the gestures and the changes of stance and displacement of weight when balancing to intercept an impending fall, but which likewise interact directly with the gaze, for example in the case of skilful evasion. The second type of likewise irreversible directions consists in the movement suggestions of figures encountering each other, with which the material body schema for the motor system cooperates under the direction of the gaze, for example when people have to get past one another without colliding on densely populated pavements ; I have mentioned this above. The concerto of emanating corporeal directions and incoming movement suggestions is sufficient for the motor orientation in corporeal communication even without consideration of areas and everything which, like positions and distances, depends on areas via reversible connections. I doubt whether animals even notice areas, and not just, like the swimmer, a dynamic volume that is not interpreted as three-dimensional. 
12 includes, besides the corporeal directions and the movement suggestions of figures encountering each other, irreversible directions of a third type : the cryptic directions. Both corporeal directions and oncoming movement suggestions have a definable source, even if this cannot be located precisely. Even the merely acoustic movement suggestions originate from a sound source. By cryptic directions I mean directions for which no source can be found. An example is the overpowering gravity that affects a person when he slips and falls, or barely manages to save himself. It comes as an outside force, as an attack from the void, over the felt body, to which it does not belong, although it is perceptible only on that body itself, not as the work of an external cause, and pulls it downwards along with the material body, although the affected person resists vigorously. Similarly cryptic are the directions of the moving emotions. I shall single out only anger. It resembles the overpowering gravity in that without a visible source, it impinges on the felt body with a considerable movement stimulus, which tends to lead forwards rather than downwards. One cannot consider, as the source, for example the object about which one is angry, with an area of condensing and a point of anchorage, for the anger does not come over one from there, but is directed in the reverse direction, against it. The sense of being seized is similar in both cases, but the behaviour in response is opposed. Whereas the person who slips and falls resists from the start, the angry person allows himself to be carried along with it, at least in an initial phase, and places his own impulse in the service of the anger, until he faces it with either surrender or resistance, and deals with it.

Everything about the human motor system that is spontaneous, fluid and involuntary, including the gestures, which are introduced spontaneously from cryptically impinging feelings and which are mostly complicated and difficult to learn, plays out in the concerto of the irreversible directions of the directional space with these three types : the corporeal directions, the oncoming movement suggestions and the cryptic directions of the emotions. All movements would become incredibly laborious and inhibited, devoid of any fluidity, if they had to be measured in locational space with positions and distances. Animals never get beyond directional space. Humans succeed in constructing a form of space of a quite different type over this, in that they are capable of recording individual targets of gazing, connecting these on surfaces through lines with reversible directions, and reading off from these connections positions and distances, with the aid of which steadfast locations can be introduced which allow one to say where something is, and if applicable allow its movement from one place to another to be followed. It is only through this that it becomes possible to store objects successively at locations, such that first one, then another object was located there. The locational space with all these achievements does not, however, take the place of directional space, but merely reshapes it and constantly relates back to it. Without fundamental directional space, there is no locational space. I have shown that this is in fact logically correct. On the other hand, everything that takes place in directional space can be translated into locational space. The result of the successful synthesis of these two forms of space is optical space. It can subside to the level of mere directional space, for example as in the spontaneous response of skilful evasion of a powerful mass seen approaching imminently. For one does not then think of locations determined by position and distance, but takes in the movement suggestion that indicates the imminent course of the mass, via a glance into the material body schema for the motor system, which adjusts one's own movement to the need for evasion accordingly. Usually, however, the visual field is organised in terms of locational 
space, but is inserted into a directional structure, adapted to the material body schema for the motor system, of looking attention. ${ }^{4}$ By contrast, the area-less space of sound does not get beyond the directional space, but it can be stored in the locational space and secondarily visualised in the imagination, in that one orientates oneself towards sources of sound. Something similar applies to the space of emotions. However, it cannot be fully stored in the locational space. Many atmospheres of emotion become apparent optically, acoustically or in imagined images of recollection or fantasy, often as atmospheres that are merely perceived or that only fleetingly touch one, even before they move one, but there are also emotions that one never sees or hears, not even when visualising them, and which nonetheless move one in a corporeally tangible way, such as when without any discernible cause, one is overcome by a sense of happiness or sinks into melancholy or despair. ${ }^{5}$ The capacity for atmospheres to be introduced into locational space does however go so far that the person can prepare his own emotional space from the emotions that have been made available to him thus at particular locations. That is what is achieved by dwelling, with which I wish to conclude this description.

Dwelling is more than satisfying physical needs through walls to protect against wind and weather, namely the art of capturing atmospheres which are emotions and designing them such that the person can attune to them in harmony with his corporeal mood. Since they, as has been shown, are aimed at claiming totally the space of experienced presence with area-less occupation, for the purpose of dwelling, in the first instance such a space must be delimited, so that they do not escape from the person's control. This purpose is served by the enclosing which separates the home from that which is outside, but which belongs with it as a contrast. Dwelling is cultivation of the emotions in an enclosed space (Schmitz 2005, p. 258-308). This definition applies not only to the domestic residence, but also to domiciles in the wider sense, such as the Christian church (as an interior space) and the garden. The shaping of emotions in an enclosed space takes place through movement suggestions and synesthetic characteristics. These are bridge qualities, which can both be sensed on one's own felt body and perceived in figures. On account of this proximity to the felt body, emotions settle on such figures that are endowed with such bridge qualities just as they move felt bodies, naturally without such figures having to feel anything because of that. Thus figures, even if they are incorporeal, become bearers of atmospheres of emotion, and these atmospheres become apparent via them, and at the same time these bearers become partners in the common drive of antagonistic encorporation, even if they themselves cannot feel anything, as for example when someone falls in love with a picture and is connected to it through the common drive, although the picture cannot feel anything. The encorporation allows the emotion that is perceived via the figure to be possessed, as his own emotion, by the conscious being that is communicating corporeally. One example: the gentle, questioning call of "hello" coming from behind, from the writer Bertolt Brecht, who up to that point was unknown to the hearer, rendered the young married journalist Ruth Berlau erotically obedient to him over the long-term, and to her misfortune. She writes about it thus: "This gentle, questioning call has, as I later discovered, for many women become so to speak the content of their lives. That is what they waited for, that is what they built on, and that is what they dreamed of" (Schmitz 2005b, p. 477). ${ }^{6}$ Brecht knew how to strike a note whose synaesthetic character was saturated with emotions, to which the dispositions of the felt bodies of the women whom he wanted to seduce were so attuned that, on account of the sound, they capitulated to him without resistance, in unilateral encorporation. 
In a comparable but more harmless way, the use of movement suggestions and synaesthetic characteristics on suitably designed objects leads to the formation of atmospheres of emotion in the enclosed space of a home, and to the tuning of the occupants and/or visitors into these atmospheres. This applies to the church space and the garden as well as to the domestic home. In this latter, the living room in particular is appointed for such cultivation of emotions which, according to the taste of the designing occupant, cultivates or subdues atmospheres through movement suggestions and synaesthetic characteristics in such a way that an emotional climate of the desired type is created. This includes the design of the walls, the ceiling and the floor (left bare or covered with carpet), as well as the furnishing and control of incoming light, temperature and sounds. In the living room, one receives one's guests, in order to demonstrate to them one's own solution to this task.

\section{BIBLIOGRAPHY}

Diels, Hermann ; Kranz, Walther. 1956. Die Fragmente der Vorsokratiker ; 1. Berlin : Weidemannsche Buchhandlung. p. XI, 504.

Mörike, Eduard. 1941. Eduard Mörikes Werke, Band. 1. Leipzig : Insel Verlag. p. 629.

Nauck, August. 1964 [1888]. Fragmenta Tragicorum Graecorum. Hildesheim : Olms. p.XXVI, 1068.

Scheler, Max. 1954. Der Formalismus in der Ethik und die materiale Wertethik. Neuer Versuch der Grundlegung eines ethischen Personalismus. Bern : Francke. p. 676.

Schmitz, Hermann. 2005a [1967]. Der leibliche Raum. System der Philosophie III Teil 1.

Studienausgabe. Bonn : Bouvier. p. XIX, 512.

Schmitz, Hermann. 2005b [1967]. Das Göttliche und der Raum. System der Philosophie III Teil 4. Studienausgabe. Bonn : Bouvier. p. XVIII, 721.

Schmitz, Hermann. 2009. Kurze Einführung in die Neue Phänomenologie. Freiburg ; München : Alber. p. 136.

Schmitz, Hermann. 2010. Jenseits des Naturalismus. Freiburg ; München : Alber. p. 319.

\section{NOTES}

1. Heraclitus fragment 45.

2. Sophocles fragment 360 .

3. Empedocles fragment 17.

4. This is shown by Kleint's swivel chair experiment, which I have discussed several times previously, firstly and in most detail in Schmitz (2005, p. 233-235).

5. Cf. Mörike's poem Verborgenheit (Mörike 1941, p. 101).

6. Quoted after : Reich-Ranicki, Marcel. 1985. Bertolt Brecht und seine Kreatur. Die Erinnerungen der Ruth Berlau. Frankfurter Allgemeine Zeitung.14 ${ }^{\text {th }}$ December 1985, Literature page. 


\section{ABSTRACTS}

The article develops a fundamental conception of atmospheres which is incorporated into a phenomenology of the felt body [Leib]. It builds on a critique of a splitting of the world into a private inner world as the location of experience and of emotions, and an external world that is separated off from that - a split already made in antiquity. Set against this notion is the conception of the felt body as space without area. What is meant by the felt body is what one can sense as belonging to oneself without recourse to the five senses. Atmospheres represent another category of spaces without area. They are regarded as a total or partial occupation of a space without area in that sphere that is experienced as being present. A distinction is made here between atmospheres of the felt body, atmospheres of emotion, and those atmospheres that are not emotions. The example of living [in the sense of dwelling] is used to clarify how people achieve their own space of emotion from the atmospheres of emotion available at places.

Cet article développe un concept d'ambiances, qui fait partie d'une phénoménologie du corps vécu [Leib]. Il se fonde sur une critique de la séparation du monde, déjà effectué dans l'antiquité, entre un monde intérieur privé comme lieu d'expériences et d'émotions et un monde extérieur. À cette idée il oppose une conception du corps vécu comme espace sans surfaces. Il associe le corps vécu à ce que l'on peut sentir comme appartenant à lui-même, sans utiliser les cinq sens. Des ambiances sont une autre catégorie d'espaces sans surfaces. Elles sont considérées comme une occupation totale ou partielle d'un espace sans surfaces dans la zone, qui est vécue comme présente. Une distinction est faite entre des atmosphères du corps vécu, des ambiances de l'émotion et de telles atmosphères, qui ne sont pas des émotions. En utilisant l'exemple de l'habiter il montre comment les êtres humains se créent leur propre espace émotionnel en partant des ambiances émotionnelles disponibles á ces lieux.

\section{INDEX}

Keywords: atmosphere, felt body, emotions, area-less spaces, phenomenology

Mots-clés: ambiance, corps-propre, émotions, espaces sans surface, phénoménologie

\section{AUTHORS}

\section{HERMANN SCHMITZ}

Hermann Schmitz est professeur de philosophie émérite. Il a été de 1971 à 1993 professeur au séminaire de philosophie de l'Université de Kiel. Il est fondateur de la Nouvelle Phénoménologie [Neue Phänomenologie].

Hermann Schmitz is a emeritus professor of philosophy. He was form 1971 to 1993 professor at the seminar of philosophy at the University of Kiel (Germany). He is the founder of the New Phenomenology [Neue Phänomenologie]. 